\title{
CALCIFICATION IN THE RENAL PAPILLA OF BEAGLE DOGS
}

\author{
Atsushi Shiga, Shinichi Mikami, Seiki Yamakawa, Hijiri Iwata, Yasuhiko \\ Hirouti, Kazuo Kobayashi, and Makoto Enomoto \\ Biosafety Research Center, Foods, Drugs and Pesticides (ANPYO CENTER)
}

\begin{abstract}
Spontaneous calcifications and depositions are common findings which occur at a high incidence inside the collecting ducts of the renal papilla in Beagle dogs. Light and electron microscopic examinations and immunohistochemistry techniques revealed that this calcium deposition occurs within the capillary venules. These lesions are evident in both male and female dogs. They are not age related, nor do they appear to progress in severity. Consistent pathological sequela include; adhesion of calcium containing macrophages to the endothelium, an influx of platelets into the endothelial cells, and projection of the endothelial basement membrane into the lumen.

Similar, non-age-related lesions are evident in the renal papilla of mice and rats and may also develop in the capillary venules of these animals. As a mechanism causing this calcium deposition, circulatory disorders may arise from anatomical and physiological alterations of the renal papilla. However, further examination should be needed for elucidation of the pathogenesis and prognosis of these lesions. (J Toxicol Pathol 6 Suppl : 37 46, 1993)
\end{abstract}

Key words: Calcification, Kidney, Laboratory Animals

\section{Introduction}

Spontaneous calcification in specific organs, unrelated to abnormal calcium metabolism, is a common finding which occurs at a high incidence in standard laboratory animals such as mice, rats, and $\operatorname{dogs} s^{1-11}$. Although extensive investigations on calcification in the renal papilla have been conducted in mice and rats, various terminologies have been used in their description in the literature, including: intratubular lithiasis, calcinosis, and mineralization ${ }^{8}$. The site of this calcium deposition is believed to occur within the collecting ducts ${ }^{8-11}$. A similar lesion, involving calcium deposition, has been described in the uriniferous tubules of the human kidney. The pathological significance, of this finding, if any, is unclear due to the fact that the human renal papilla is rich in

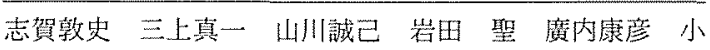
林和雄 楆本 畺

Accepted for publication: July 16, 1993

Mailing address: Atsushi Shiga, Department of Veterinary Pathology, School of Veterinary Medicine, Azabu University, Sagamihara, Kanagawa 229, Japan.
}

capillary venules, collecting ducts, and loops of Henle. Therefore, accurate and definite diagnosis is complicated in determining the site of deposition utilizing classical light microscopy.

This paper describes the findings of light and electronmicroscopic examinations of calcium deposition in the renal papilla of Beagle dogs. Additional examinations are also presented to compare these findings with spontaneously occurring deposits of calcium in the brain of mice, the kidney of rats, and the stomach of dogs.

\section{Materials and Methods}

Renal tissue was obtained from control male and female dogs, twelve months of age, that were purchased from Hazleton Co., Ltd. (U.S.A.) and utilized in subchronic, safety evaluation studies conducted at the An-Pyo Center. Kidneys were fixed in $10 \%$ neutral, bufferd formalin, processed and embedded in paraffin. Sections $(3 \mu \mathrm{m})$ were stained with hematoxilin and eosin (HE). Selected sections were stained with von Kossa's, Pearls and alizarin red stains. The Mc Gee-Rus- 
sel method was used to detect calcium content histochemically. PAS (with and without digestion), Gomori's one step trichrome stain, PTAH, PAM, and 10\% nitric acid treatment were also utilized to identify the nature of these deposits. These evaluations were performed on the brains of $\mathrm{B} 6 \mathrm{C} 3 \mathrm{~F} 1$ mice, 109 weeks of age and on the kidneys of Fischer 344/Crj rats, 20 weeks of age : Charles River Japan. Serial sections, stained with H.E., were made along the sites of calcium depositions and related surrounding tissue. Anti-swine vimentin antibody (Dako corp.), anti-human keratin antibody (Dako corp.), Wheat Germ Agglutinin (WGA) (Dako corp.), and anti-human factor VIII related antigen antibody (Dako corp.) were applied to $3 \mu \mathrm{m}$ sections from paraffin embedded tissue by indirect immunoenzyme assay using streptavidin biotin method (DAKO LSAB KIT) to identify the exact site of calcium deposition. Sections were counterstained with Mayer's hematoxilin. Kidney tissue for electron microscopic evaluations was prefixed in $2 \%$ glutaraldehide and $2.5 \%$ paraformaldehide at $4{ }^{\circ} \mathrm{C}$ for more than 3 days. Selected specimens were postfixed in $1 \%$ osmium tetroxide in $0.1 \mathrm{M}$ cacodylate buffer for 2 hours at $4^{\circ} \mathrm{C}$, processed as usual and embedded in a mixture of Epon 812 and Araldyte. Semithin sections were cut and stained with $1 \%$ toluidine blue for selection of the object site. Ultrathin sections were then cut at the corresponding site and stained with $4 \%$ uranyl acetate and lead citrate. These sections were examined with transmission electron microscopy, Hitachi $\mathrm{H}-1000$ at $75 \mathrm{kV}$. De--epoxyed semithin sections stained with $\mathrm{HE}$ stain and PAS were prepared and observed microscopically to identify the corresponding site selected.

\section{Results}

\section{Light microscopy}

Calcium deposits were seen within the lumens at the renal papilla in the specimens stained with hematoxilin-eosin. Althogh most of them were basophilic, some were stained reddish violet. A variety of structures were evident, such as lamellar, amorphous and granular ones. Erythrocytes or leukocytes were seen occasionally (without hematuria) in the same lumen (Fig. 1), otherwise the lumens were filled only with calcium deposits (Fig. 2). Serial sections of the tissues demonstrated that either the lumens containing calcium deposits were connected to the vascular spaces or that a cellular reaction occurred (Fig. 1). The lumens containing calcium deposits, in particular, were filled with erythrocytes when the kidney was exsanguinated incompletely. All calcium deposits of a variety of structures showed the same histochemical reaction. The results of special staining

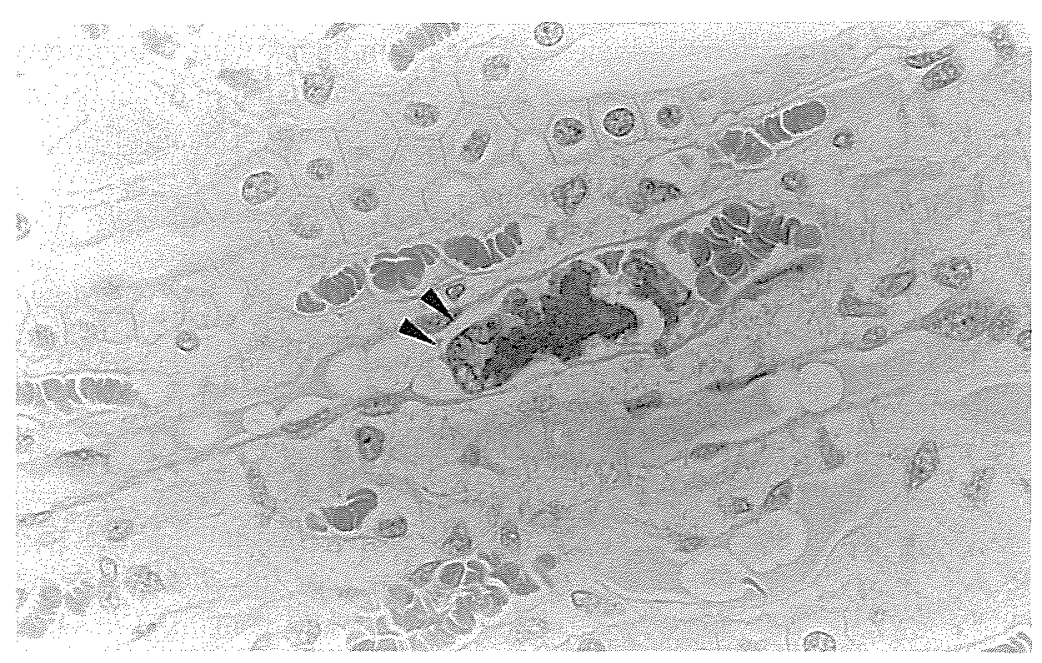

Fig. 1. Calcium deposits with coexisting erythrocytes in the lumen. Cellular reaction against the deposits (arrowhead), HE $\times 400$ 


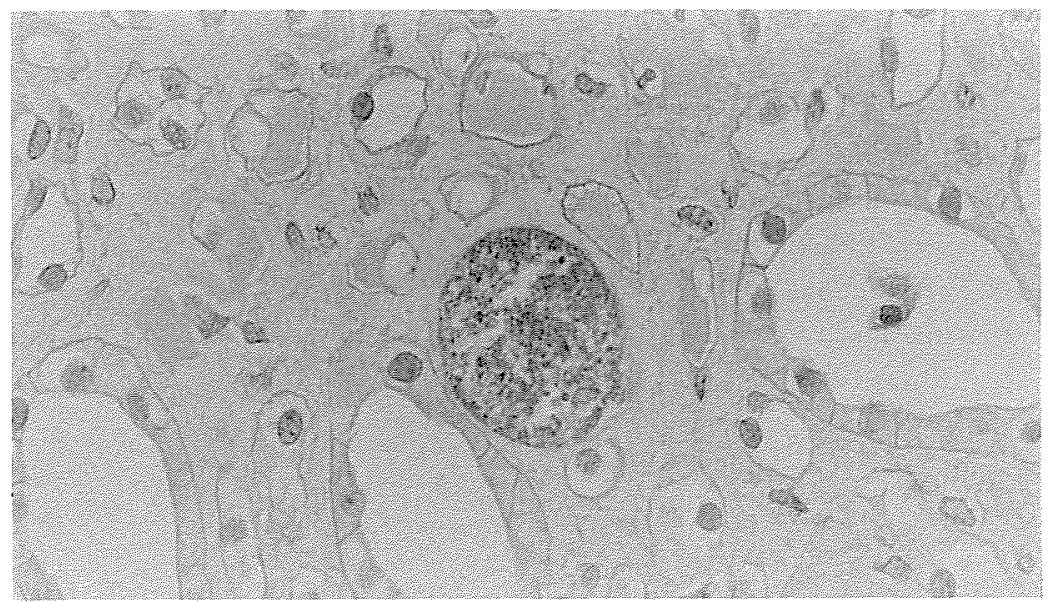

Fig. 2. Granular calcium deposits occupying the lumen. $\mathrm{HE} \times 400$

Table 1. Comparison of Staining Methods for Calcium Deposits

\begin{tabular}{lcccc}
\hline & Dog Kidney & Dog Stomach & Rat Kidney & Mouse Brain \\
\hline von Kossa's method & + & + & + & + \\
Alizarin red (Darhl's method) & + & + & + & + \\
P.A.S. reaction (diastase digestion) & + & + & + & + \\
$-\quad$ (partial) & (partial) & (partial) & (partial) \\
Pearls method (Berlin blue) & + & + & + & + \\
Kernechtrot & + & + & + & + \\
McGee-Russel's method & reb, blue & red, ble & blue & red, blue \\
Gomori's one step trichrome & & (partial) & & + \\
& $+*$ & + & UN & + \\
P.T.A.H. stain & & (partial) & & (partial) \\
10\% nitric acid & resistant & resistant & solution & resistant \\
\hline
\end{tabular}

*: Peripheral, UN : unknown, calcium deposits disappeared during staining procedure.

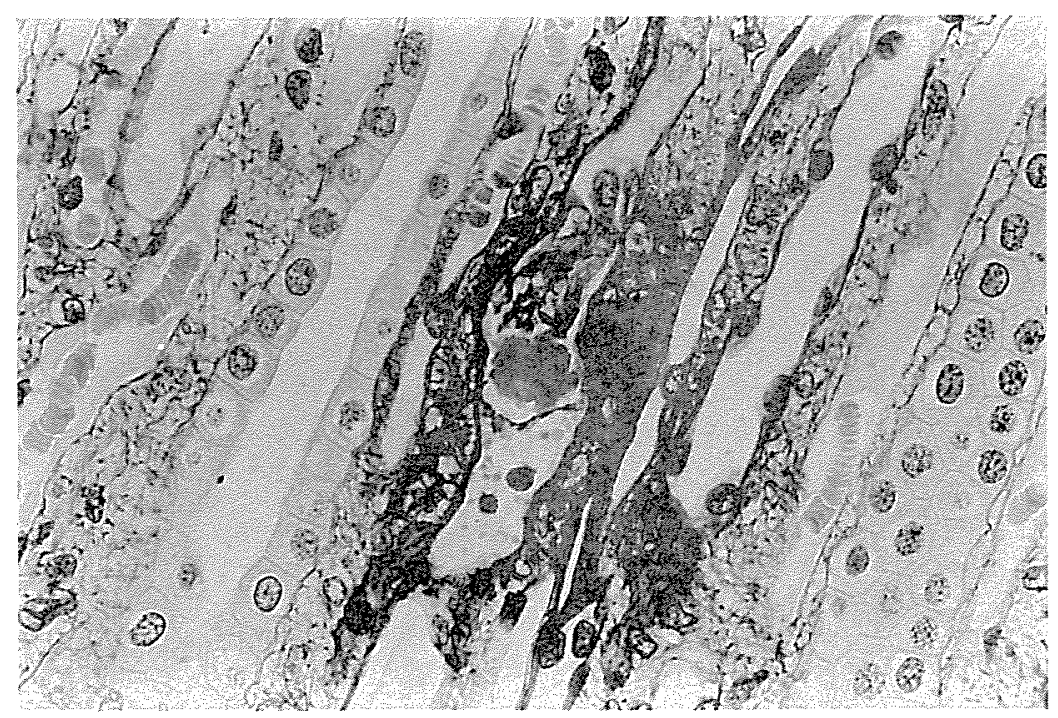

Fig. 3. Basement membrane projecting into the lumen. Cellular reaction is evident. PAM $\times 400$ 
for calcium deposits of Beagle dogs were similar to the spontaneously occurring deposits in the other species as shown in Table 1. However, the stain reaction of deposits in Beagle dogs seemed to be weak for von Kossa's stain when compared to those of the other species. Parts of the deposits stained with PTAH were homogeneously positive except in dogs showing an irregularly positive reaction. The PAM stain demonstrated that the basement membrane was protruded into the lumen (Fig. 3).

\section{Immunohistochemistry}

The lining cells of the lumen containig calcium deposits react positively to anti-swine vimentin antibody (Fig. 4) but not to anti-human

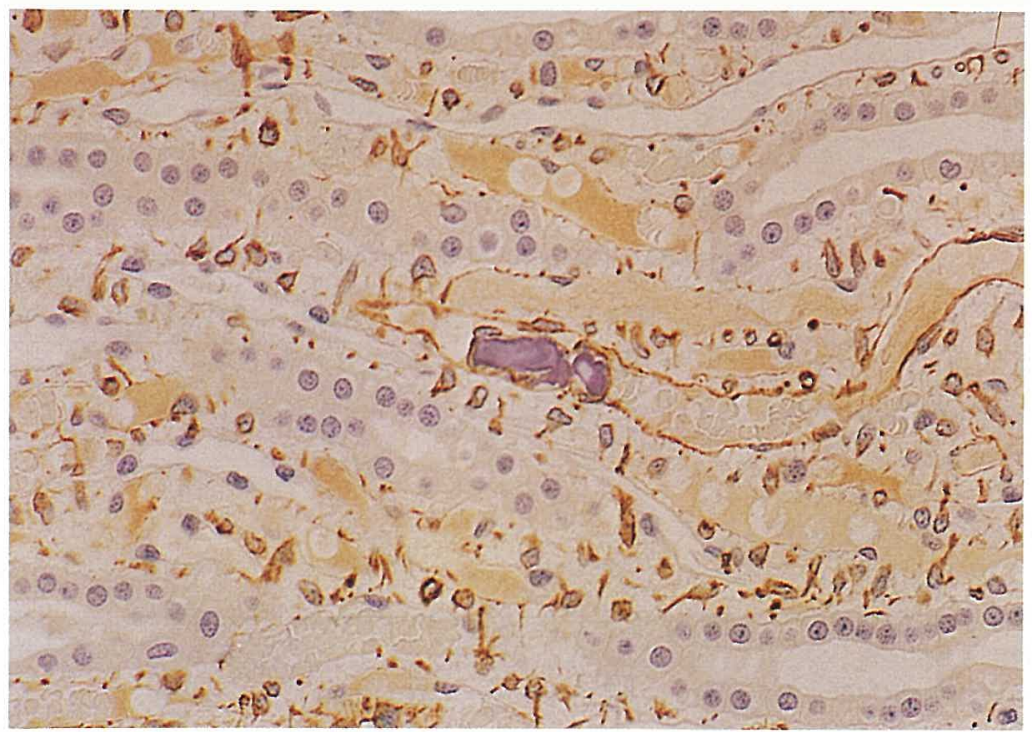

Fig. 4. Immunoperoxidase staining with anti-swine vimentin antibody, counterstained with Mayer's hematoxilin, $\times 300$

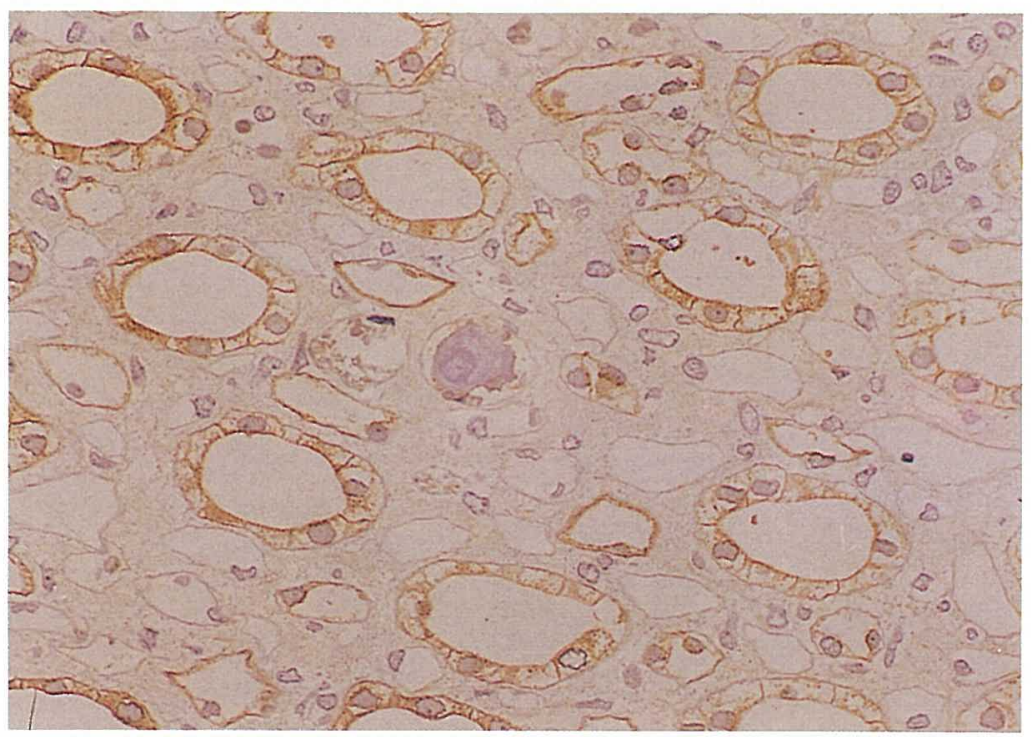

Fig. 5. Immunoperoxidase staining with anti-human keratin antibody, counterstained with Mayer's hematoxilin, $\times 300$ 
keratin antibody (Fig. 5). Calcium deposits were seen occasionally in the vimentin-positive cell. Human factor VIII related antigen was present in the endothelial cells of vessels larger than capillary vessels in the kidney, but was not evident in the capillary vessels of the renal papilla. Lectins WGA reacted positively with the endothelial cells of the renal papilla and also to the epithelial cells

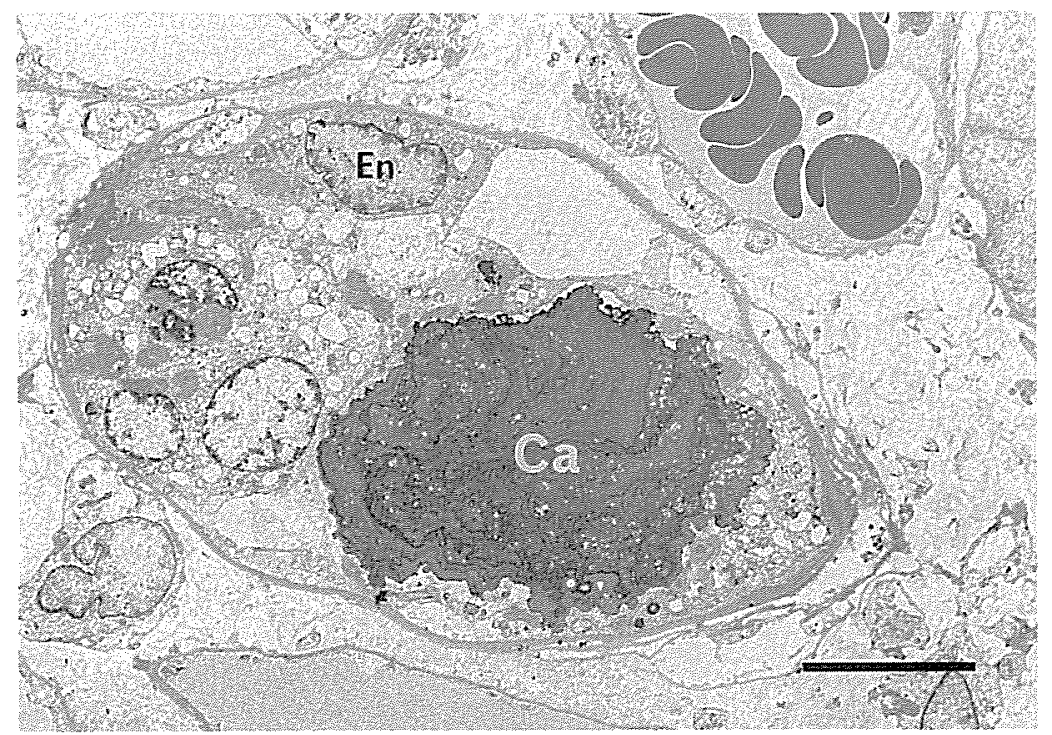

Fig. 6. The basement membrane of the lumen containing calcium deposits is thickened irregulary. The deposits are electron dense with lamellar structures.

Many types of cells are seen in the lumen. Ca: Calcium deposits, En : Endothelial cell, TEM, uranyl acetate and lead citrate, $\mathrm{Bar}=10 \mu \mathrm{m}$.

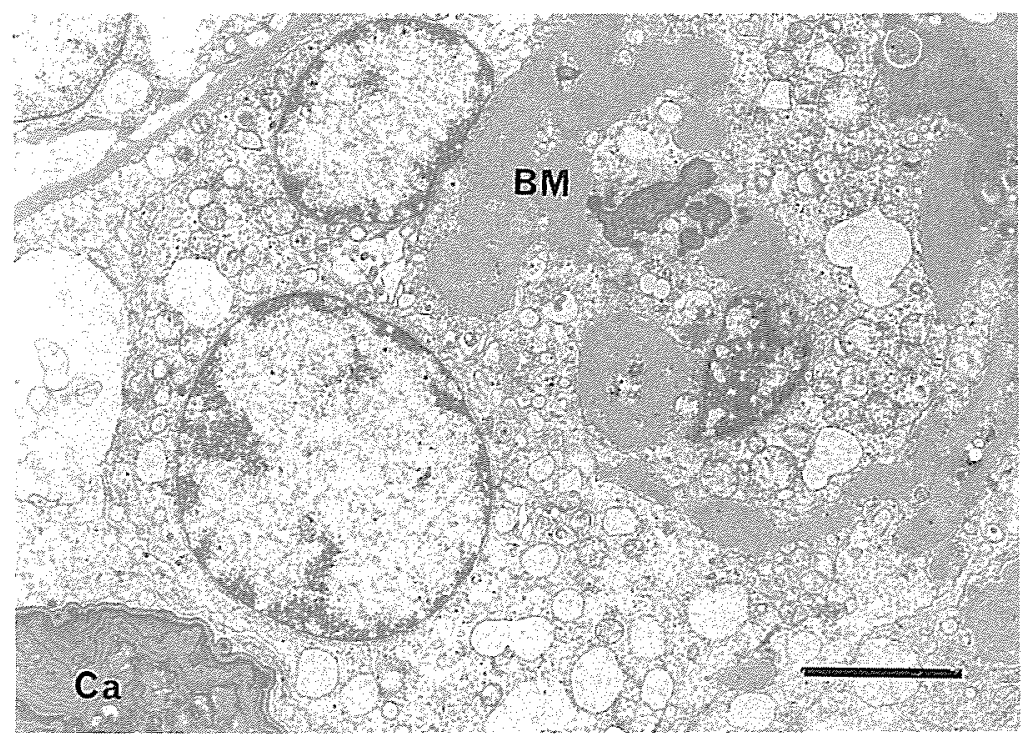

Fig. 7. High magnification of Fig. 6.

Macrophage (monocyte) adhered to the lumen. The cell contained calcium deposits and a few electron lucent amorphous materials (Basement membrane-like: BM). Ca: Calcium deposits, TEM, uranyl acetate and lead citrate, $\mathrm{Bar}=2 \mu \mathrm{m}$ 
of the Henle's loop and collecting ducts.

\section{Electronmicroscopy}

Materials diagnosed as calcium deposits by light microscopy as having lamellar or amorphous structures showed similar concentric lamellar or amorphous, electron dense structures under electron microscopy. The deposition sites of calcium

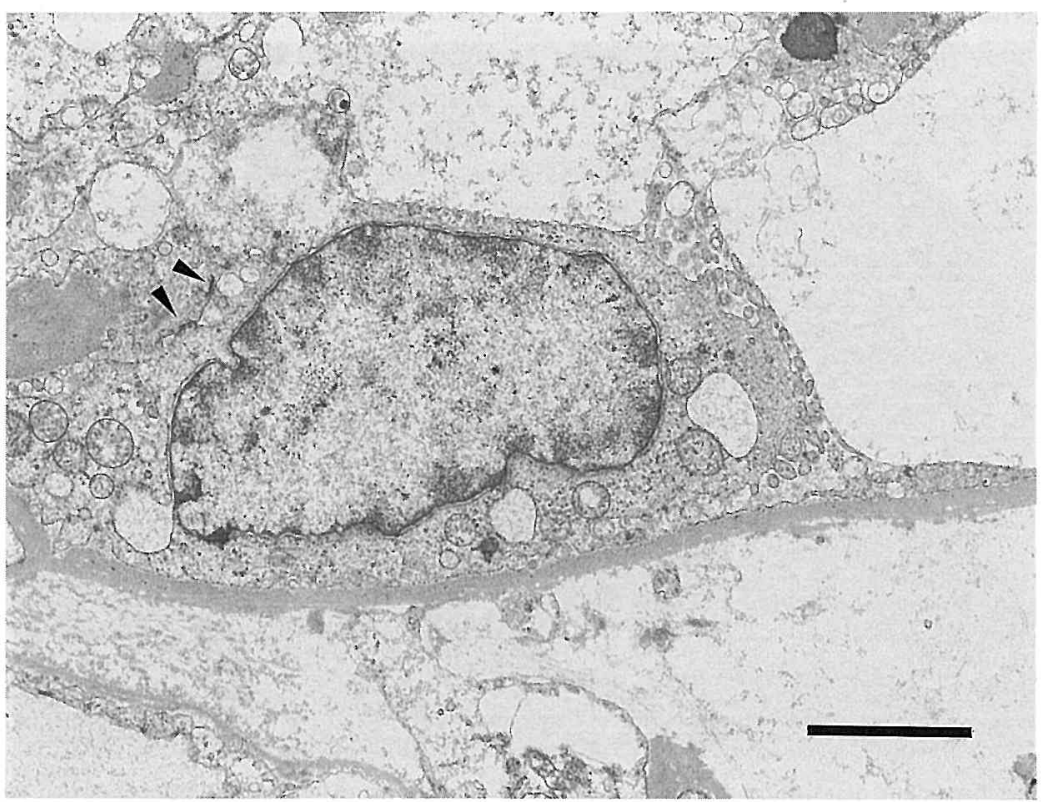

Fig. 8. High magnification of Fig. 6.

Endothelial cell lining the lumen with calcium deposition.

A junctional complex was formed between this cell and the macrophage (arrowhead).

TEM, uranyl acetate and lead citrate, $\mathrm{Bar}=2 \mu \mathrm{m}$.

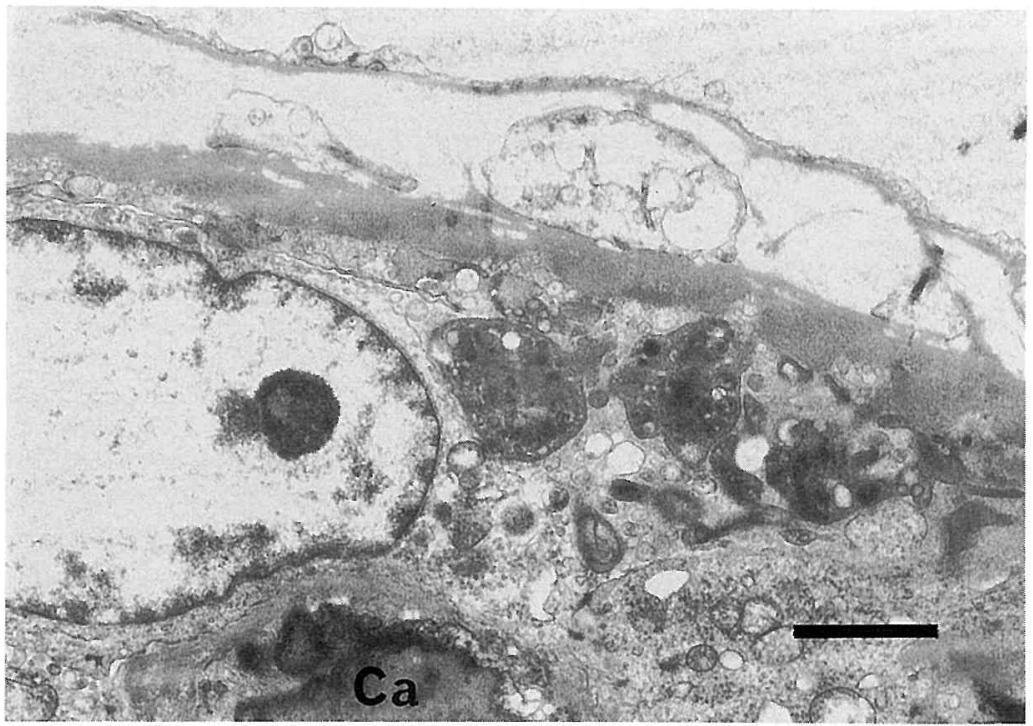

Fig. 9. Section obtained from the same specimen as Fig. 6. Endothelial cell lining the lumen where calcium is deposited. A few platelets are seen in the cytoplasm. Ca: Calcium is deposits, TEM, uranyl acetate and lead citrate, $\mathrm{Bar}=3 \mu \mathrm{m}$. 
were in the cytoplasm or the basement membrane of the lumen. The latter was irregularly thickened when compared to the capillary vessels, Henle's loop, or collecting ducts (Fig. 6). Calcium deposits were also observed in the basement membrane. A number of vacuoles, mitochondria, and free ribosomes were observed in the cells containing calcium deposits. Furthermore, cytoplasmic filaments measuring about $5 \mathrm{~nm}$ in width were occasionally seen and arranged irregularly. Many fine cell processes, sometimes slender, developed on the cell surface. Figure 7 shows cell contain-

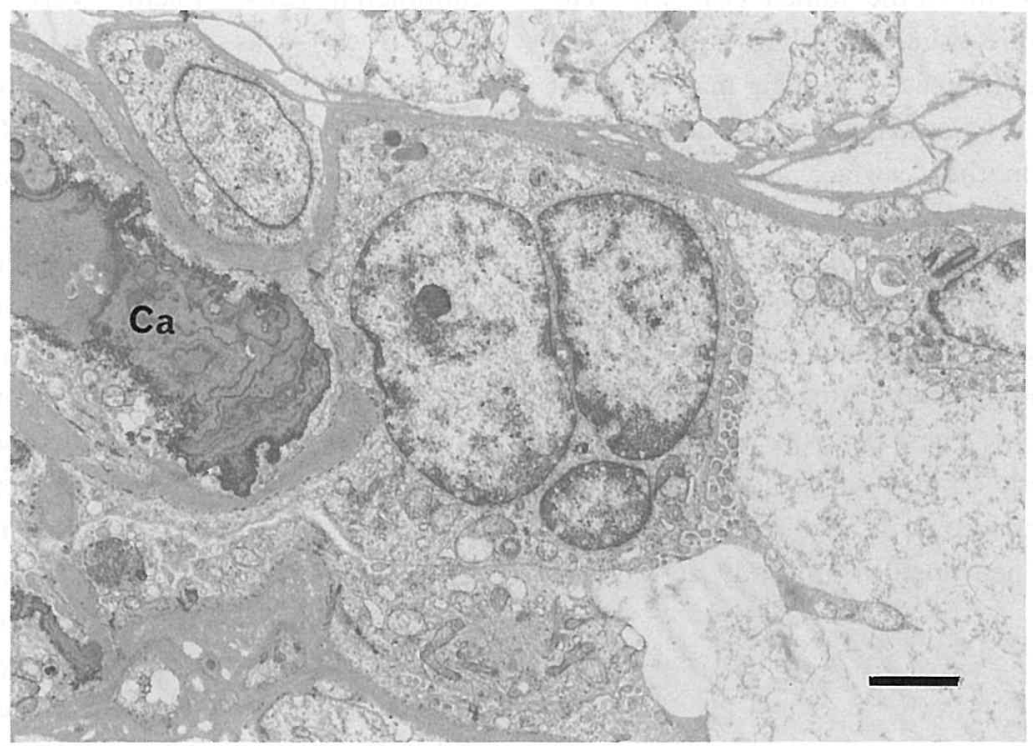

Fig. 10. Another field in the same section as Fig. 7.

Adhesion of macrophage to the lumen. Projection and thickening of basement membrane. Ca : Calcium deposits. TEM, uranyl acetate and lead citrate, Bar $=4 \mu \mathrm{m}$.

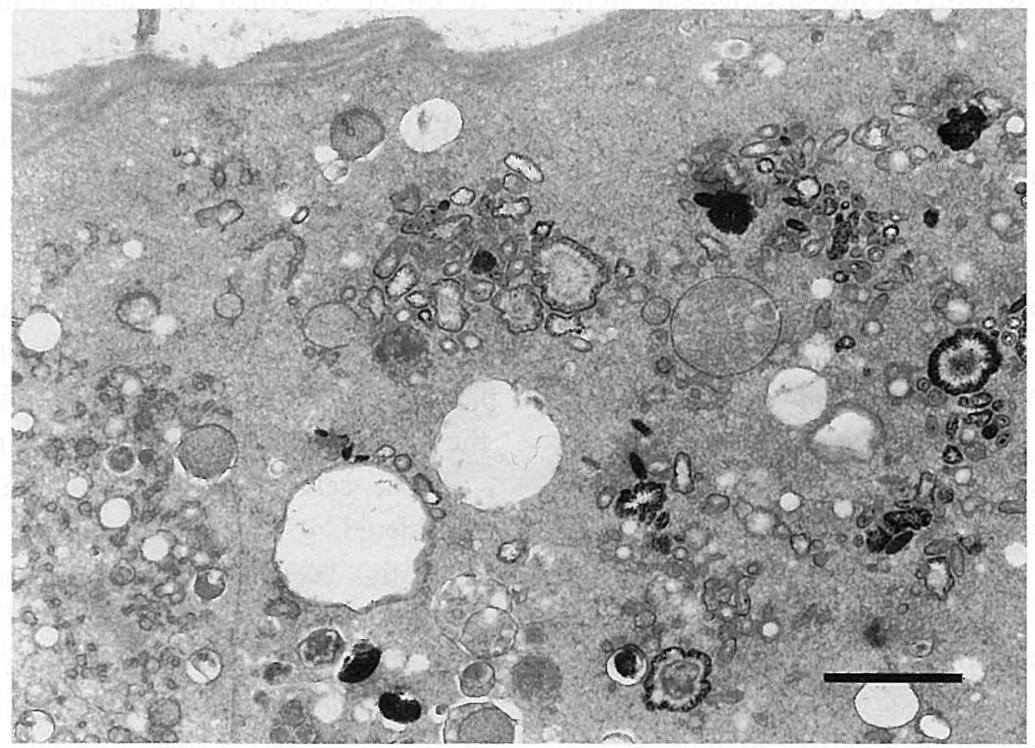

Fig. 11. Electron micrograph of Fig. 2.

A variety type of crystalline materials. No cellular elements are observed. TEM, uranyl acetate and lead citrate, $\mathrm{Bar}=2 \mu \mathrm{m}$. 
ing small calcium deposits with some electron leucent morphous aterial. These cells also contained many vacuoles, mitochondria and free ribosomes and showed microvillae on the cell surface. In addition, nuclei containing abundunt heterochromatin were evident. Junctional complexs were formed between these cells and neighboring flat cells lining the lumen (Fig. 8). The mitochondria were usually swollen and the electron density was decreased in their matrix. Flat cells had a relatively few organellaes, but had short cell processes on their surface and occasionally contained a few platelets in the cytoplasm (Fig. 9). The cell adhering to the basement membrane separating into double structures is seen projecting into the lumen (Fig. 8). Granular calcium deposits filled lumen and no cell lining at the wall was observed (Fig. 2). These deposits were composed of yarious materials both morphologically and in density electronmicroscopically (Fig. 11). Reaction to anti-swine vimentin antibody at this site was unclear.

\section{Discussion}

Calcification occurs at a high incidence spontaneously in the brain of mice and in the kidneys of rats and dogs. Yanai et al. (1984) have shown that the calcium deposits in the vascular wall in the thalamus of mice developed initially on the basement membrane. The components of the deposits were examined by using $\mathrm{X}$-ray microanalysis ${ }^{12}$. This finding was considered to be an age-related change. Many aspects of the calcification, including incidences and sex related differences were reported previously ${ }^{5}$. No strain difference was shown in mice or rats. Since calcification in the kidney of rats occurring at the cortico-medullary junction was likely to be a sex-related change, experimental studies on the nutritional or hormone dependent factors in pathogenesis were conducted $^{13-15}$. Calcium deposits disappeared in ovaryectomized rats 4 weeks of age but not in rats 16 weeks of age $^{15}$. Most investigators contend that calcium is deposited within the uriniferous tubule at the cortico-medullary junction, due to shedding of the vesiculated microvilli and microvesicles from the epithelium of S1 segment of the proximal renal tubule ${ }^{8}$. Woodard (1971) further demonstrated both intraluminal and intracellular deposits ${ }^{13}$.

Antibody against vimentin and factor VIII related antigen or several lectins such as Wheat Germ Agglutinin and Griffonia sinplicifolia-I (GS-I) were utilized as marker for normal canine endothelial cells. Factor VIII related antigen (FVIIIRAg) was considered to be a reliable marker for canine vascular endothelial cells as Takeda et al. (1991) reported ${ }^{16}$. However, it reacted in endothelial cells of vessels larger than capillary vessels but not in capillary vessels of the renal papilla in this study. Kinjo et al. (1989) reported that the vascular endothelial cells in different anatomic compartments of human kidney expressed heterogeneous surface antigens and those of the renal papilla were negative for FVIIIRAgi7 .

Similar findings were also seen in the dogs. Augstin-Voss (1990) reported that normal canine cutaneous endothelial cells binded to several lectins such as GS-I, Neu-Peanut agglutinin (Neu-PNA), Ricinus communis agglutinin (RCAI), Neu-Soybean agglutinin (Neu-SBA), WGA, and Neu-Wheat germ agglutinin (Neu-WGA), moderately ${ }^{18}$. However, Holthöfer (1983) examined lectin binding sites in the kidney with 14 animal species and showed that lectins also reacted to either proximal or distal tubules ${ }^{19}$. In this study both endothelial cells and epithelial cells reacted positively to WGA. Therefore, lectins were considered to be inappropriate markers for the distinction of both cell types. Vimentin was believed to be present in mesenchymal cells such as endothelial cells and fibroblasts. In this study, both epithelial cells of Henle's loop and the collecting ducts did not react with vimentin. Therefore, it was considered to be the most reliable marker for the identification of canine capillary vessels.

The cells containing calcium deposits were considered to be macrophages electronmicroscopically, because of the presense of numerous organellaes. These macrophage-like cells which was filled with many mitochondria and rough endoplasmic reticulum and a few lysozomes (myelinozomes), were also observed in the lumens of vessels. Microvilli developed on the surface of these cells and the adjacent endothelial cells also 


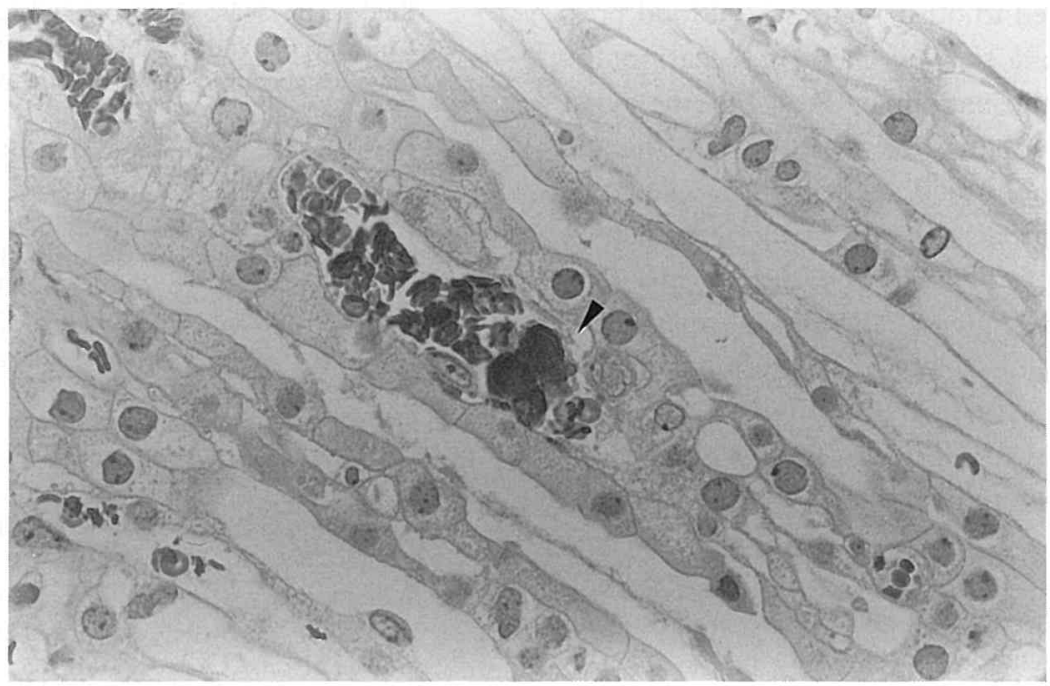

Fig. 12. Calcium deposits in the renal papilla of mouse.

HE $\times 400$

developed relatively long cytoplasmic processes. Kinjo et al. (1989) speculated that peritubular endothelial cells in the medullary interstitium share antigens with a monocyte subset in the peripheral blood ${ }^{17}$. Endothelial cells seem to activate the adhesive molecules participating in the adhesion of lymphocytes and monocytes. Nagura (1991) further clarified that the endothelial cells not only line the vascular lumen but also serve as effector cells for immune responses ${ }^{20}$.

Calcification was most marked after 8 weeks of feeding a semipurified diet to rats ${ }^{13}$. However, a granulomatous inflammatory reaction appeares to accompany these deposits at the final course of the reaction. How calcification progresses and disappears in the renal papilla of dogs is unknown. Although the incidence is low, similar lesions are also observed in the renal papilla of mice and rats (Fig. 12). Calcification in rats, is observed within the collecting ducts and does not elicit a host response $^{7}$. Since no advanced lesion is observed in rats, whether this lesion is identical to that in the dog is not known. All spontaneous calcifications in mice and rats are basophilic. Some of the calcium deposits in dogs are slightly eosinophilic and is probably due to the calcium-salt ratio in these deposits. So-called calcification in the renal papilla of Beagle dogs may not be an age-related change and/or not due to sex differences. The site of calcium deposits in the renal papilla was considered to be inside the collecting ducts of uriniferous tubule as is the case with calcification in rats. The present study has shown that: the calcium deposits coexisted with erythrocytes in the lumen, some of this lumen adhered to the vessels, a cellular reaction was seen around the calcium deposits, all calcium deposits were seen in the lumen lined by the vimentin positive cells, calcium deposits were not found in the lumen lined by the keratin-positive cells, and that the cells of the wall containing the calcium deposits were endothelial cells, electronmicroscopically. These findings revealed that calcification in the renal papilla of Beagle dogs was seen in the capillary vessels. Recently, Shupe et al. (1992) observed calcium deposits in the renal papilla of cows exposed to fluoride for over 25 years. They stated that mineral deposits were associated with the medullary vascular plexus rather than lower nephron segments ${ }^{21}$.

There are no lymphatics in the renal inner medulla. The capillaries forming the plexus are lined with a thin fenestrated endothelium. The plasma protein concentration in descending vasa recta (DVR) was shown to be 1.8 times that of the systemic blood and even higher at the tip of the papilla than DVR at the base. Average circulating time is long and blood flow is slow in the 
papilla, compared to other regions ${ }^{22}$. Blood pressure at the papilla showed $0 \mathrm{mmHg}$, occasionally. Consequently, the endothelial cells in the renal papilla are likely to be effected by substances contained in the blood. The findings include adhesion of the macrophages to the endothelum, influx of platelets into the endothelial cells, and projection of the endothelial basement membrane into the lumen and are considered to reflect pathological effects. Although the prognosis of these lesions is unknown at present, further elucidation is planned for the future.

Acknowledgement: The authors wish to thank Dr. William J. Tierney, Tierney \& Associates Inc., for his kind reading of the manuscript.

\section{References}

1. Yanai, T, Kudo, K, Manabe, J, and Matsunuma, N : Spontaneous Vascular Mineralization in the Brain of Aged B6C3F1 Mice. Jpn J Vet Sci 46: 761-765, 1984.

2. Enomoto, $\mathbf{M}$ and Akazaki, $\mathbf{K}$ : Color Atlas of Toxicologic Pathology, pp. 175, Soft Science Publications, Tokyo, 1987 (in Japanese)

3. Greaves, P and Faccini, JM : Rat Histopathology, pp. 145-146, Elsevier, Amsterdam, 1992.

4. Faccini, JM, Abott, DP, and Paulus, GJJ, Mouse Histopathology, pp. 193-195, Elsevier, Amsterdam, 1990.

5. Ward, JM, Goodman, DG, Squire, RA, Chu, KG, and Linhart, MS: Neoplastic and non-neoplastic lesions in aging $(\mathrm{C} 57 \mathrm{LB} / 6 \mathrm{~N} \times \mathrm{C} 3 \mathrm{H} / \mathrm{HeN}) \quad \mathrm{F} 1$ (B6C3F1) mice., J Natl Cancer Inst 63: 849-854, 1979.

6. Benirschke, K, Garner, FM, and Jones, TC: Pathology of Laboratory Animals, Vol. I, Springer-Verlag, New York, 1978.

7. Montgomery, $\mathrm{Jr}$ and Seely, JC: Kidney. In : Boorman, G.A. et al. (Eds) Pathology of Fischer Rat. Academic Press, California, 1990.

8. Greaves, P., Histopathology of Preclinical Toxicity
Studies, pp. 546-547, Elsevier, Amsterdam, 1990.

9. Cousins, FB and Geary, CPM : A sex-determined renal calcification in rats. Nature, 211: 980-981, 1966.

10. Glaister, JR : Principles of Toxicological Pathology, Taylor \& Francis London, 1986.

11. Morishima, H, Nonoyama, T, Sasaki, S, and Miyajima, $\mathrm{H}$ : Spontaneous lesions in beagle dogs used in toxicity studies., Exp Anim 39: 239-248, 1990.

12. Yanai, T, Yamato, T, Manabe, J, Takaoka, M, and Matsunuma, N : X-ray microanalysis of mineralization in the thalamus of aged mice. Jpn J Vet Sci 49 : 920-922, 1987.

13. Woodard, JC: A morphologic and biochemical study of nutritional nephrocalcinosis in female rats fed semipurified diets. Am J Pathol 65: 253-268, 1971.

14. Woodard, JC: Relationship between the ingredients of semipurified diets and nutritional nephrocalcinosis of rats. Am J Pathol 65: 269-278, 1971.

15. Iwata, $\mathrm{H}$, Yasuhiko, $\mathrm{H}$, Inoue, $\mathrm{H}$, and Enomoto, $\mathrm{M}$ : Pathological study on nephrocalcinosis in fischer 344/Du Crj rats. Exp Anim 35: 299-305, 1986.

16. Takeda, T, Makita, T, Nakamura, N, and Kimizuka, $\mathrm{G}$ : Morphologic aspects and morphogenesis of blood cysts on canine cardiac valve. Vet. Pathol. 28: 16-21, 1991.

17. Kinjo, T, Manehisa, T, Miyake, $\mathrm{K}$, and Nagura, $\mathrm{H}$ : Phenotypic heterogeneity of vascular endothelial cells in the human kidney. Cell Tissue Res. 256 27-34, 1989.

18. Augustin-Voss, HG, Smith, CA, and Lewis, RM: Phenotypic characterization of normal and neoplastic canine endothelial cells by lectin histochemistry. Vet Pathol 27 : 103-109, 1990.

19. Holthöfor, H: Lectin binding sites in kidney: A comparative study of 14 animal species. J Histchem Cytochem 31: 531-537, 1983.

20. Nagura, $\mathrm{H}$ : The immunofunction of vascularendothelial cells, Byori To Rinsho 9: 26-32, 1991 (in Japanese).

21. Shupe, JL, Brunner, RH, Seymour, JL, and Alden, CL: The pathology of chronic bovine fluorosis: A review. 20 : 274-285, 1992.

22. Zimmerhackl, BL, Robertson, CR, and Jamison, RL: The medullary microcirculation., Kid Int 31 : 641-647, 1987. 